

\section{Flowers for Algernon}

by Daniel Keyes. First published 1958. New York: Harcourt, Inc. Harvest Books, 2004.

Flowers for Algernon was the first occasion that our Neurology Book Club participants agreed that the book was too short! A classic of science fiction from 1958, it tells the story of Charlie, a man with learning difficulties who undergoes a procedure to enhance his intelligence. The procedure was tested on a mouse called Algernon but Charlie is the first human to have it. Unfortunately, it becomes apparent that the benefits of the procedure are not permanent, and as Charlie sees Algernon deteriorate he faces up to his own impending deterioration. The story is told as Charlie's diary, documenting his hopes, fears and experiences.

Its style is reminiscent of Ray Bradbury or other classics of the 1950s and 1960s. Despite this, it is not especially dated and still seems very relevant today. It is perhaps fortunate that the details of the neurosurgical procedure are glossed over, although the neurosurgeon in our group was sorry not to know more. It is primarily an exploration of intelligence: what it is, what it means to be intelligent, and what life is like for people at opposite extremes of the intelligence spectrum, where too much or too little intelligence can be a significant impediment. However, for much of the book, intelligence is almost synonymous with memory: this stimulated vigorous debate but we agreed it was too limited a definition.

Because the story is written from Charlie's viewpoint, the style changes dramatically throughout the book as his intelligence waxes and wanes. We felt that this illustrated how everyone experiences the same intensity of emotion, although not everyone can articulate it clearly: this may be clinically relevant particularly when caring for patients with learning difficulties, or those with functional neurological disorders.

Most of our discussion centred upon Charlie's relationships with other people, and how his changing intelligence affects them. As his intelligence increases, so he loses his previous friends, and also as he looks back on previous events he increasingly realises that these so-called friends have not treated him kindly. We spent some time discussing whether he was happier at low intelligence, and whether he realised at the time that he had in fact been treated badly. We also noted the effect of a learning disabled relative on a family-given the significant strain on Charlie's parents' marriage as well as concerns about whether his sister would be affected by having such a brother. We reflected the importance of considering patients in the context of their families, and how the fading away of memory, intellect and self in patients with dementia can be more distressing for the family than the patient.

We also discussed Charlie's relationship with the scientists, feeling sometimes uncomfortable to read how they treated him. In particular, we noted important lessons in gaining consent from patients to participate in research projects. Although Charlie was obviously keen to contribute to science, we doubted that he was ever fully informed or whether his consent was valid for the neurosurgical procedure.

Later in the book, it becomes apparent that the scientists' main aim was to further their own careers, rather than Charlie's welfare. There are many instances when he is not treated as a person in his own right. In addition, from Charlie's point of view he was disappointed to find that at his peak his intelligence exceeded that of the scientists; he had been hoping to befriend them but instead finds himself increasingly isolated. He seemed socially 'locked out' when he had learning difficulties and when he was very intelligent, but only realised it properly when he was intelligent.

Flowers for Algernon deserves its reputation as a classic, and our group felt it was worth reading for many reasons, being thought provoking and entertaining, as well as raising important issues around clinical ethics and good medical and scientific practice.

Katharine Harding

Correspondence to Dr Katharine Harding,

Department of Neurology, University Hospital of

Wales, Cardiff CF14 4XW, UK; katharineharding@

doctors.org.uk

Twitter Follow Katharine Harding at

@ drkatharineh

Competing interests - None declared.

Provenance and peer review

Commissioned; internally peer reviewed. 